\title{
Saberes indisciplinados: os conteúdos da história na escola e as aprendizagens para a vida
}

Undisciplined knowledge: the contents of history in school and learnings for life

Sandra Regina Ferreira de Oliveira*

\section{RESUmo}

Como ensinar História em uma sala de aula de alunos repetentes com muitos, muitos problemas? Investigamos como potencializar o processo de ensino e aprendizagem desses alunos. $\mathrm{O}$ caminho metodológico pautou-se em ações nas quais os alunos puderam se reconhecer como sujeitos, reconhecer o outro e se reconhecer no outro. Utilizamos técnicas de filmagem, fotografia, autofotografia e rodas de discussões. O objetivo foi construir um ambiente que propiciasse o desenvolvimento de noções de identidade e alteridade. Os resultados alcançados comprovaram em parte nossas hipóteses iniciais, mas também indicaram novas perspectivas e desafios. Este artigo é parte das ações do Projeto Pibid-Pedagogia da UEL, e conta com o apoio financeiro da Capes.

Palavras-chave: ensino de História; identidade; alteridade.

\section{Abstract}

How does one teach History in a class of failing students with many, many problems? We investigated how to enhance these students' teaching and learning processes. The methodology was based on actions in which the students could recognize themselves as individuals, recognize each other and recognize themselves on the other. We used filming, photographs, projections and collective discussions as techniques. The goal was to build an environment which would provide the development of notions of identity and otherness. The results achieved partially confirmed our initial hypotheses, but also showed new perspectives and challenges. This article is part of actions of Pibid Project-Pedagogy of UEL, and relies on the financial support of Capes.

Keywords: teaching of History; identity; otherness.

\footnotetext{
* Centro de Comunicação, Educação e Artes, Departamento de Educação, Universidade Estadual de Londrina. Rodovia Celso Garcia Cid, PR 445, km 380, Campus Universitário. Caixa Postal 10011.86057-970 Londrina - PR - Brasil. sandra.oliveira@sercomtel.br
} 
A frase "É preciso saber viver", muito além de um refrão de música, revela uma complexidade que enfraquece o anúncio de qualquer outra ideia importante. Uma frase composta por verbos que nos desafiam a pensar sobre nossa constituição como seres humanos e a necessidade que temos em aprender saberes que nos propiciem viver em sociedade.

A escola, ou, mais precisamente, a sala de aula, foi compreendida neste texto com base no princípio anunciado logo no início: um lugar como tantos outros, de aprendizagem de saberes necessários para a vida. Porém, a complexidade que se encerra no que definimos por 'vida' não se encaixa na forma pela qual trabalhamos com os saberes na escola.

$\mathrm{Ou}$, dito de outra forma: nos saberes escolares, muitas vezes, não há espaço para a vida. Apropriando-nos das reflexões de Pineau e Le Grand ${ }^{1}$ sobre histórias de vida e aproximando-as de nosso objeto de discussão (a escola), perguntamo-nos: o fato de considerar a vida em sua totalidade não vai de encontro ao paradigma disciplinar que recorta essa vida em pedaços para compreendê-la?

O obstáculo que se coloca para professores, formadores de professores e pesquisadores, ao assumir a escola como lugar de aprendizagem para a vida e sobre a vida, é vencer a ideia de que tal posição afasta a escola de sua função como lugar de saberes científicos, "por isso, torna-se problemática a presença semiclandestina, não apenas dessa noção, mas, sobretudo, dessas práticas indisciplinadas" (Pineau; Le Grand, 2010, p.86).

Esse desafio começa a ser enfrentado ao assumirmos dois argumentos: primeiro, que o conhecimento científico também compõe o que denominamos 'vida' e, desapegado da sua relação com a busca dos seres humanos por 'aprender a viver', torna-se estéril e sem significado para ser ensinado na escola. Em segundo lugar, é preciso assumir que, na escola mais do que em qualquer outro espaço, interagem diferentes tipos de conhecimentos que compõem a 'vida', e essa situação é muito salutar para o processo de aprendizagem de qualquer conhecimento científico.

Forquin considera a escola inserida em um determinado contexto cultural e social, que dialoga com as demandas desse mundo quanto aos saberes a serem trabalhados. Esse autor adverte, porém, que a escola "não pode tampouco estar completamente a reboque desta demanda, nem se regular por ela, seguindo mimeticamente todas as suas expressões, todas as suas contradições e todas 
as suas metamorfoses". ${ }^{2}$ Estaríamos à frente de uma questão paradoxal? Como aliar o ensino de conhecimentos científicos com a aprendizagem de saberes necessários para a vida?

A resposta que conseguimos construir no desenvolvimento do projeto discutido neste texto transita por entender os problemas cotidianos como elementos propulsores de uma prática pedagógica voltada para resolução de problemas, de forma tal que as reflexões atinjam patamares diferenciados quanto ao uso do conhecimento. Trata-se de entender a escola como lugar no qual se faz possível obter

respostas a questões que não seriam jamais colocadas em outros lugares. Aqui a herança da experiência humana é comunicada sob a forma mais universal possível, isto é, também a menos 'concreta', a menos pertinente em relação às interrogações pontuais, aleatórias ou rotineiras suscitadas pelas situações triviais da vida. (Forquin, 1993, p.169)

São muitos os problemas, questões ou indagações que podem ser colocados em análise no espaço escolar. Alguns advindos do desejo do professor em propor situações desafiadoras, instigantes e capazes de mobilizar os alunos na busca dos saberes necessários ao processo de solução dos problemas. Trata-se, nesse caso, de problemas planejados com intuito pedagógico de potencializar o processo de ensino e de aprendizagem dos conteúdos elencados como importantes para serem ensinados na escola. Na maioria das vezes, conteúdos referendados pela tradição curricular.

A relação entre resolução de problemas e aprendizagem é postulada por diversos autores, dentre os quais destacamos Jean Piaget. ${ }^{3}$ Para esse autor, o sujeito frente a uma situação-problema, ou seja, uma situação que não é resolvida por meio dos conhecimentos que já possui, busca outros saberes com o intuito de ultrapassar a barreira da não possibilidade. Aliamo-nos àqueles que defendem um ensino, em qualquer área de conhecimento, pautado no espírito investigativo, porque aprender é estabelecer relações entre informações, produzindo conhecimento no intento de solucionar problemas de diferentes tipologias.

Na esteira dessa definição, entende-se que ensinar algo na escola é propor problemas, gerar demandas que precisam ser resolvidas com base em determinados saberes, com ênfase progressiva na utilização do saber científico. No 
decorrer de nossas vidas, dentro e fora da escola, as não possibilidades se apresentam das mais variadas formas e não podem ser agrupadas em fáceis ou difíceis. Tornar possível o que em algum momento nos é impossível é o grande desafio e força motriz na produção do conhecimento.

As situações-problema planejadas são, portanto, estratégias pedagógicas importantes, e revestem de significância o ensino e a aprendizagem de muitos conteúdos. Há, entretanto, outra tipologia de problemas no cotidiano escolar que, geralmente, são compreendidos como empecilhos para o trabalho do professor e, consequentemente, apontados como justificativa para um baixo nível de aprendizagem por parte dos alunos.

Neste texto, dedicamo-nos a analisar os contrastes e nuanças de uma sala de aula com muitos problemas, e acompanhar as estratégias desenvolvidas por acadêmicas de Pedagogia no Programa Institucional de Bolsa de Iniciação à Docência (Pibid). ${ }^{4}$ A ideia inicial era trabalhar com a temática "Patrimônio Histórico" junto a turmas de $3^{a}$ série (faixa etária de 8 anos) de escolas públicas municipais da cidade de Londrina, no Paraná. Em algumas escolas o trabalho foi plenamente realizado. Em uma delas o cenário encontrado obrigou-nos a buscar outros caminhos.

No ano de 2011, no processo de adaptação ao ensino fundamental de 9 anos, os alunos que em 2010 frequentavam a 2a série e não conseguiram, por diversos fatores, a aprovação para a $3^{\text {a }}$ série, não tinham como frequentar a turma do $2^{\circ}$ ano do ensino de 9 anos, pois, em termos de faixa etária, essa turma corresponde à $1^{\text {a }}$ série do ensino de 8 anos. Na tentativa de minimizar os problemas, foram agrupados em uma sala de $3^{\text {a }}$ série os alunos reprovados na $2^{\text {a }}$ série, em 2010.

O fato gerou uma atmosfera de fracasso, frustração e conformismo com a situação de não aprendizagem, tanto por parte dos alunos como dos professores. A existência da sala especificada, ainda que não tenha sido este o objetivo, gerou uma situação-problema, tanto para a escola como para o nosso grupo de estudos, do qual também participavam os alunos pibidianos.

As explicações sobre a dificuldade dos alunos e a quase aceitação de que pouco poderia ser feito ancoravam-se, principalmente, no fato de que a grande maioria dos alunos em questão era proveniente de famílias com muitos problemas. O comportamento das crianças em questão refletia-se no linguajar, nos hábitos e na relação com a professora e os demais colegas, evidenciando o estado 
de abandono no qual se encontravam. Em síntese, não era um comportamento que se aproximasse do mínimo esperado pelos professores para desencadear um processo de aprendizagem sobre os mais variados assuntos. Os alunos agrediam-se constantemente, andavam pela sala e não se dispunham a fazer qualquer atividade que exigisse um pouco mais de esforço cognitivo. O desgaste da professora era intenso. O cansaço e o desânimo estavam estampados nas olheiras que, dia após dia, marcavam seus olhos. O único recurso era trabalhar com propostas que não colocassem os alunos em situação de exigência.

A primeira tentativa de desenvolvimento do trabalho sobre "Patrimônio Histórico" com essa turma foi um fracasso. Os alunos não pararam sequer para ouvir a proposta, então a professora aconselhou a estagiária pibidiana a não prosseguir com a aula, voltando às atividades simples e à conversa espontânea entre e com os alunos.

Dias depois, durante o grupo de estudo, a estagiária pibidiana que vivenciou a situação afirmou, com os olhos marejados, a um passo de desistir do projeto: "a gente fica discutindo sobre a importância da História... Na sala que estou, não dá para ensinar História nem outra matéria. Eles [os alunos] não têm respeito por mim e pelos colegas; eles não sabem viver juntos...". Um silêncio assustador fez-se presente e todos voltaram os olhos para mim, na expectativa de uma resposta. Rapidamente, outra aluna argumentou que, talvez, fosse mais adequado retirar o projeto dessa sala para evitar atrasos no cronograma, visto que o trabalho com as outras salas desenvolvia-se sem maiores transtornos. Antes da minha intervenção, ouvi as seguintes palavras, entre soluços, raiva e desespero: "mas eles [os alunos] seriam abandonados de novo".

Decidimos, então, não desistir, e contamos com o apoio e a dedicação de professoras que acreditaram e ousaram buscar outros caminhos. O tema "Patrimônio Histórico" continuou a ser trabalhado normalmente com as demais turmas, e com essa específica escolhemos trabalhar o tema "Identidade e Alteridade”, na tentativa de promover alterações na convivência social.

O que aconteceu com os alunos limítrofes, agressivos e indisciplinados? Aprenderam a conhecer e superar suas dificuldades cognitivas, a dialogar com o outro na tentativa de resolver os problemas, e, principalmente, aprenderam a viver junto ao outro, em sociedade, o que requer sempre controle e disciplina, aliados à liberdade e autonomia. Este texto é sobre essa história. 
O que se relata neste texto ocorreu no ano de 2011. Um ano depois, o tema "Patrimônio Histórico", como planejado, foi desenvolvido junto a esses alunos com resultados impressionantes quanto à aprendizagem dos conteúdos históricos, geográficos e matemáticos e quanto à produção de texto. Mas isso é tema para outro artigo.

\section{OS SABERES INDISCIPLINADOS E A LÓGICA DAS DISCIPLINAS ESCOLARES}

Compreendemos que aprender a viver em sociedade não é uma situação rotineira, tampouco trivial, e são muitos os saberes envolvidos nessa seara. Saberes que, como os demais, são ensinados e aprendidos em vários espaços sociais. A escola é um desses espaços, mas à medida que os alunos crescem, é comum na cultura escolar separar os saberes científicos, ensinados como conteúdos das disciplinas escolares, dos saberes necessários para viver em sociedade. Esses saberes extrapolam a lógica disciplinar, assim como extrapolam o espaço e o tempo escolar. Por isso a ousadia em denominá-los 'saberes indisciplinados'.

Tratando-se dos anos iniciais do Ensino Fundamental, faixa de escolaridade foco deste artigo, os problemas gerados no processo de convivência social são desafiadores e carregados de possibilidades para o ensino de História. Um dos conteúdos clássicos para esse nível de ensino é o trabalho com a identidade, com a história de vida dos alunos, de suas famílias, enfim, com questões relacionadas a seu entorno, capazes de desencadear noções de pertencimento a determinado grupo social. Pois bem, como poderíamos desenvolver um trabalho com esses alunos, aliando o que precisávamos ensinar quanto ao conhecimento histórico e o que se fazia necessário aprender para melhorar o nível de socialização? Seria possível encontrar um denominador comum para essa situação?

O conceito de identidade foi compreendido com base nas contribuições de Bauman, ${ }^{5}$ que destaca o fato de estarmos expostos, simultaneamente, a várias comunidades de ideias e princípios. Na sala de aula em questão era notório que os alunos constituíram, por suas relações familiares, formas de agir que não se adequavam às esperadas para o contexto escolar. No entanto, essa forma de agir retratava o que cada um trazia de seu contexto, de 'sua gente'. Essa 
forma de ser e de agir era a identidade que conferia a eles segurança para sobreviver em um espaço com o qual não se identificavam.

Historicamente, o conceito de identidade, para Bauman, relaciona-se com o domínio do espaço geográfico e a constituição do Estado moderno, e altera-se na contemporaneidade em virtude do uso da tecnologia que redimensiona a noção de tempo e espaço, estabelece outras formas de estar junto nas redes sociais e influencia mudanças na identidade pessoal. A navegação em redes sociais não é recorrente entre as crianças com as quais trabalhamos, apesar de todas conhecerem computador e terem, vez ou outra, usado a lan house do bairro. O que nos interessa é cotejar o cenário da sala de aula com as ideias de Bauman, para compreender a importância que os alunos davam ao domínio e poder sobre o espaço e ao que entendiam por relacionar-se com o outro.

Sem dúvida, o ambiente familiar é o primeiro lugar de relacionamento com o outro. A compreensão que adquirimos de nós mesmos e dos outros carrega as marcas dos primeiros 'modelos de gentes' com os quais deparamos. Montoya afirma que "a estrutura social e familiar modela a comunicação e a linguagem e essas, por sua vez, modelam o pensamento e o estilo comunicativo que se revelam na solução dos problemas". ${ }^{6}$

Entendemos por ambiente familiar o lugar em que são supridas as necessidades básicas do ser humano desde a mais tenra idade. O que somos constitui-se na relação estabelecida com as pessoas que cuidam de nós, nosso primeiro ponto de apoio para crescer e evoluir. De qualquer forma, todos os alunos daquela sala foram cuidados por alguém e tiveram suas necessidades básicas supridas para que pudessem sobreviver. Ocorre que viver envolve aspectos muito mais complexos do que os essenciais para a sobrevivência. $O$ ensino e a aprendizagem de diferentes saberes na escola só são possíveis se nos situarmos no campo da vida, e não apenas da sobrevida.

Não é possível trabalhar com o tema "Identidade e Alteridade" em sala de aula sem adentrar aspectos que nos levam a pensar sobre quem somos nós. No entanto, a pergunta “Quem você é?" só tem sentido quando há espaço para viver. No estreito espaço da sobrevivência são poucas as alternativas possíveis.

Afinal de contas, perguntar 'quem você é só faz sentido se você acredita que possa ser outra coisa além de você mesmo; só se você tem uma escolha, e só se o que você escolhe depende de você; ou seja, só se você tem de fazer alguma coisa para que a escolha seja 'real' e se sustente. (Bauman, 2005, p.26) 
Muito cedo, em suas sobrevidas, essas crianças entendem a existência de fatores que são possíveis para os outros e não para elas. Esse entendimento é forjado e reforçado diariamente no embate das lutas sociais, e incide na ideia de identidade. Por esse caminho é possível compreender, entre outras questões, por que famílias de baixa renda dispõem de recursos importantes da receita familiar para comprarem celulares modernos para seus filhos, ou explicar por que a prostituição se faz presente cada vez mais cedo na vida dos nossos jovens, permitindo-lhes acesso a recursos financeiros com os quais compram artefatos da cultura contemporânea que, na concepção deles, conferem pertencimento a determinados grupos sociais. Ainda que pareça insensato, trata-se de uma luta para não aceitarem o lugar que lhes é destinado a sobreviver neste mundo.

É comum estabelecermos uma relação de causa e efeito entre condição financeira e dificuldade de aprendizagem que, em sua maioria, relaciona-se com a ausência de uma postura padrão esperada para frequentar os bancos escolares. Sabemos que são muitas as variáveis a serem analisadas quando se discute a razão pela qual os alunos não aprendem e não absorvem o conteúdo. A questão econômica, assim como o perfil familiar, não pode ser apontada como a única ou a mais importante característica a ser analisada.

Ao selecionar os conteúdos da História e a metodologia a ser utilizada em sala, tem-se um recurso importante que contribui na interpretação de si e dos outros, na compreensão de quem somos, do que podemos ser e do entendimento e valorização de nossas bagagens sociais, trazidas da convivência familiar. Acontece que, muitas vezes, ao trabalhar com conceitos de temáticas do tipo 'quem sou eu' e 'família', por exemplo, reforçamos um modelo que segrega e afasta aqueles que não se moldam ao padrão sugerido como ideal.

Justificamos a não aprendizagem indicando que o aluno está fora do padrão. Nesse não lugar encontram-se os alunos que repetem o ano, abandonam a escola; aqueles que vivem à custa da Bolsa Família, que convivem com viciados em drogas, com presidiários e ex-presidiários, com prostitutas, com traficantes; os que moram em lares formados por casais homossexuais, e os que provêm de famílias agnósticas - enfim, todos aqueles que, por diferentes aspectos, não se ajustam ao modelo. Quando alguém ousa questionar tal pressuposto, a resposta é uníssona e nos salva do desafio de romper com o preconceito: 'fulano é exceção'. 
Recorrendo à perspectiva da epistemologia genética, Montoya explicita que a construção do conhecimento resulta da interação entre o sujeito consciente de si mesmo com os outros, assim como com os objetos já constituídos. Ao nos afastarmos de modelos e promovermos o autoconhecimento e o respeito mútuo, abre-se espaço para que as noções de identidade e alteridade sejam apreendidas. Contudo, em uma sala onde existem constantes conflitos e agressões físicas, esse espaço é inexistente.

A forma inicial que encontramos para abrir esse espaço foi o uso da tecnologia e da linguagem imagética. A linguagem televisiva é usual na vida dos alunos, e vários comportamentos agressivos e ofensas verbais são repetições e/ ou adaptações de cenas assistidas na televisão.

Em 1995, Moran pontuava sobre o uso de vídeo:

TV e vídeo encontraram a fórmula de comunicar-se com a maioria das pessoas, tanto crianças como adultas. O ritmo torna-se cada vez mais alucinante (por exemplo nos videoclipes). A lógica da narrativa não se baseia necessariamente na causalidade, mas na contiguidade, em colocar um pedaço de imagem ou história ao lado da outra. A sua retórica conseguiu encontrar fórmulas que se adaptam perfeitamente à sensibilidade do homem contemporâneo. Usam uma linguagem concreta, plástica, de cenas curtas, com pouca informação de cada vez, com ritmo acelerado e contrastado, multiplicando os pontos de vista, os cenários, os personagens, os sons, as imagens, os ângulos, os efeitos. ${ }^{7}$

Escolhemos o tema "Amizade" para o trabalho com filmes, e nos preocupamos em selecionar filmes curtos, mas que não infantilizassem mais os alunos. Segundo Moran,

As linguagens da TV e do vídeo respondem à sensibilidade dos jovens e da grande maioria da população adulta. São dinâmicas, dirigem-se antes à afetividade do que à razão. O jovem lê o que pode visualizar, precisa ver para compreender. Toda a sua fala é mais sensorial-visual do que racional e abstrata. Lê, vendo. (Moran, 1995, p.29)

Após a apresentação dos vídeos, pequenas rodas de discussão foram realizadas no intuito de perguntar o que os alunos tinham compreendido. O tema "Amizade" favoreceu, em parte, a disposição de cada um em participar da roda, suscitando um ambiente menos agressivo. Entretanto, nas primeiras rodas foi 
necessário conter os alunos utilizando recursos como: intercalar meninos e meninas; utilizar saquinho de sorteio para que cada um, se quisesse, expressasse sua opinião; usar a ampulheta para dar um tempo máximo e igual para todos. Recursos simples, mas que colocam as pessoas em situação de igualdade, fator importante na constituição de um lugar seguro, no qual cada um possa ser o que realmente é.

Vencemos as duas primeiras etapas: os alunos pararam para assistir aos vídeos e conseguimos conversar em roda com menos interrupções advindas de pequenas agressões físicas e verbais. Usamos a ideia de 'não aula' como estratégia de aproximação aos alunos.

O vídeo está umbilicalmente ligado à televisão e a um contexto de lazer, é entretenimento, que passa imperceptivelmente para a sala de aula. Vídeo, na cabeça dos alunos, significa descanso e não 'aula', o que modifica a postura, as expectativas em relação ao seu uso. Precisamos aproveitar essa expectativa positiva para atrair o aluno para os assuntos do nosso planejamento pedagógico. Mas ao mesmo tempo, saber que necessitamos prestar atenção para estabelecer novas pontes entre o vídeo e as outras dinâmicas da aula. (Moran, 1998, p.78)

Todas as ações foram gravadas com a devida autorização dos envolvidos e seus responsáveis. Ao analisá-las, identificamos que as narrativas orais (forma possível para aqueles alunos naquele contexto) construídas pelos estudantes pautavam-se na descrição das imagens vistas. Segundo Custódio, "sabe-se que o ser humano é bombardeado o tempo todo por estímulos, dos quais pelo menos a metade - alguns teóricos dizem até $75 \%$ - é visual. Outros $20 \%$ são auditivos". ${ }^{8}$ O desafio era passar da descrição para a interpretação dos filmes.

Planejamos, com o auxílio da professora, a etapa posterior: produzir um texto sobre a temática citada. Retomou-se a situação dos alunos já descrita aqui: frente a qualquer situação na qual se fizesse necessário um saber mais sistematizado, no caso o domínio da escrita, desencadeavam-se diversas situações de conflitos na sala, as quais culminavam em confrontos físicos.

Optamos por solicitar uma produção pequena, dirigida ao outro, e que colocasse os alunos na situação de explicar o que entendiam por amizade. $\mathrm{O}$ gênero escolhido foi o classificado de jornal devidamente estudado: o que era, qual a finalidade e as diferentes tipologias. Os alunos foram desafiados a procurar um amigo utilizando-se desse recurso, e o resultado obtido ultrapassou 
as expectativas, mas também criou algumas situações de conflito, porque adentramos, pouco a pouco, o conhecimento de si e dos outros.

Para Montoya, um dos principais problemas das crianças com dificuldade de aprendizagem é a falta de oportunidade de realizar trocas simbólicas no meio social, ou seja, exteriorizar suas impressões. Tal fato prejudica o processo de construção do conhecimento, porque sem troca, sem retorno dos outros, $o$ sujeito não tem elementos balizadores que permitam entender a si próprio. No conjunto (e vagamente), a atividade proposta (assistir aos vídeos, ouvir e falar nas rodas, estudar sobre o classificado, fazer o classificado e, finalmente, expor a todos o seu trabalho) reforçou a interiorização do conceito apresentado e levou os alunos a exteriorizarem suas impressões do que entendem por amizade.

A narrativa torna-se, então, o elemento-chave para entender a ação da linguagem e do meio social no processo construtivo do pensamento, isto é, no processo da interiorização ou de conceptualização das ações (Custódio, 2011, p.106-107). Nesse sentido, a roda de discussão é um procedimento inigualável para criar uma atmosfera propícia para construções de narrativas orais, ponto de partida para os mais variados diálogos. Quanto mais informal, melhor: no chão, sem nenhum material, sem posição de hierarquia entre professores e alunos, em contato direto uns com os outros, em uma disposição que favorece a troca, pois "Num meio social onde os adultos estejam dispostos a compartilhar as indagações da criança, onde se possa ouvi-la, onde se possa solicitar a reconstituição das suas ações, o processo da reconstrução das ações será favorecido e garantido" (Custódio, 2011, p.109).

Depois de quase 2 meses, entre altos e baixos, conseguimos um nível de socialização que nos permitiu iniciar o trabalho com o tema "Identidade e Alteridade". Continuamos utilizando a análise da imagem como recurso central do trabalho, no entanto, nesse momento, os filmes e as fotografias seriam dos próprios alunos, coletados nas etapas anteriores de trabalho e baseados na realização de novas filmagens. A ideia era propor reflexões acerca do comportamento deles mesmos e dos demais colegas. O olhar para o outro, a exotopia e o olhar para si poderiam propiciar uma compreensão melhor de si e dos outros, favorecendo alterações no relacionamento dos alunos.

Conforme Bakhtin, 
reagimos com um juízo de valor a todas as manifestações daqueles que nos rodeiam: na vida, todavia, nossas reações são díspares, são reações a manifestações isoladas e não ao todo do homem, e mesmo quando o determinamos enquanto todo, definindo-o como bom, mau, egoísta etc., expressamos unicamente a posição que adotamos a respeito dele na prática cotidiana, e esse juízo o determina menos do que traduz o que esperamos dele; ou então se tratará apenas de uma impressão aleatória produzida por esse todo ou, enfim, de uma má generalização empírica. Na vida, o que nos interessa não é o todo do homem, mas os atos isolados com os quais nos confrontamos e que, de uma maneira ou de outra, nos dizem respeito ... é ainda em nós mesmos que somos menos aptos para perceber o todo da nossa pessoa. ${ }^{9}$

Durante as filmagens realizadas nas diferentes etapas de trabalho, alguns alunos criaram 'personagens heroicos' e passaram a agir de maneira diferente da habitual. A criação desses personagens é citada por Bakhtin:

De acordo com uma relação simples [entre autor e herói], o autor dever situar-se fora de si mesmo, viver a si mesmo num plano diferente daquele em que vivemos efetivamente nossa vida; essa é a condição expressa para que ele possa completar-se até formar um todo graças a valores que são transcendentes à sua vida, vivida internamente, e que lhe asseguram o acabamento. Ele deve tornar-se outro relativamente a si mesmo, ver-se pelos olhos de outro. (Bakhtin, 1992, p.35)

Na concepção de cada um, os 'heróis' foram criados: alguns auxiliaram a professora na correção da tarefa, outros passaram em frente à câmera de filmagem, outros ficaram quietos, e alguns ainda atrapalharam a correção com brincadeiras, para provocar risos.

O herói revelará muitos disfarces, máscaras aleatórias, gestos falsos, atos inesperados que dependem das reações emotivo-volitivas do autor ... O artista que luta por uma imagem determinada e estável de um herói, luta, em larga medida, consigo mesmo. (Bakhtin, 1992, p.26-27)

$\mathrm{Na}$ devolutiva dos vídeos, a luta com si mesmo se fazia presente e a rota de fuga era esquecer-se de si e focar a análise no outro. Como a roda não tem início nem fim, de alguma forma o olhar do outro levava o sujeito a olhar para 
si mesmo: "Depois de vermos a nós mesmos pelos olhos de outro, sempre regressamos a nós mesmos" (Bakhtin, 1992, p.37).

O trabalho com os vídeos da turma e com a autofotografia (aquela que os jovens tiram de si mesmos e postam nas redes sociais) proporcionou adentrar um pouco mais na forma como cada um se entendia. Não foi um trabalho para fracos. Contudo, as abordagens anteriores sobre amizade criaram um cenário favorável para a realização das rodas de discussão sobre os vídeos. Após algumas rodas, sempre acompanhadas de atividades que exigiam construções de narrativas sobre diversas temáticas, iniciamos a última etapa de trabalho: "Identidade e Alteridade" a partir da questão "Quem você é?".

A proposta de pensar sobre sua identidade aliava-se à reflexão sobre a situação de não aprendizagem. Qual o entendimento que aqueles alunos tinham sobre o fato de estarem agrupados em uma sala? Como se sentiam em relação aos demais colegas da escola? Foi inquietante identificar a nítida compreensão que tinham sobre a situação de exclusão à qual estavam submetidos. Concluímos que uma das explicações para a forma como se comportavam em sala de aula relacionava-se com a revolta que sentiam por serem alunos daquela turma. Tinham noção de que estavam em uma situação diferenciada na escola, alocados em um espaço destinado aos 'incapazes de aprender'.

$\mathrm{Na}$ roda de discussão, refletiu-se sobre o que cada um sabia fazer bem, o que sabiam fazer de maneira razoável, e o que lhes proporcionava muita dificuldade. Nesta última categoria, os alunos incluíram todos os afazeres relacionados à escola, principalmente ler, escrever e fazer contas. Colocamos em discussão como e por que eram capazes de memorizar a letra de uma música e cantá-la inteira e tinham dificuldade para ler e escrever palavras e números; ou então, como apresentavam dificuldade para realizar uma operação de subtração no caderno, mas sabiam perfeitamente conferir o troco quando compravam balas no bar em frente à escola.

Fomos mapeando com os alunos algumas circunstâncias em que havia mais motivação e interesse do que em outras. No desenrolar dessas conversas, identificamos que o feedback negativo recebido durante a tão curta e já comprometida história escolar de cada um pesava muito na compreensão que teciam sobre suas capacidades cognitivas. Sabemos que crianças que recebem constantemente devolutivas negativas têm menor probabilidade de serem realistas e efetivas no seu dia a dia, e têm mais probabilidade de manifestar 
padrões de comportamento anticonvencionais. A devolutiva de pessoas significantes como pais, professores e amigos tem grande importância na vida desses alunos, assim como na vida de todos nós.

Todos os trabalhos realizados com a turma, desde então, finalizavam com rodas de discussões, cuja devolutiva pautava-se em três categorias: o que estava muito bom, o que precisava melhorar um pouco e o que precisava melhorar muito. Um feedback claro, positivo, aliado ao desafio de propor desafios para ampliar o cabedal de conhecimento, uma prática pedagógica essencial nos anos iniciais do Ensino Fundamental. É nesse período que as crianças constroem um conjunto de crenças sobre a sua capacidade intelectual e psicossocial, basilares para o sucesso escolar.

Bem, o ano terminou e não abordamos vários conteúdos que precisavam ser trabalhados. 'Perdemos muito tempo' nas rodas de discussões, filmagens, fotografias, e nem temos a certeza de que conseguimos trabalhar a contento com o tema ao qual nos dispusemos: "Identidade e Alteridade".

Em 2012, essa turma frequentou a então denominada $4^{a}$ série, e, um ano depois do previsto, trabalhamos com o tema "Patrimônio Histórico". Todavia, o tempo e a experiência nos mostraram que estávamos certos em apostar no ensino do que se fazia necessário naquele contexto em 2011: "Identidade e Alteridade", com foco nas relações sociais. Finalizamos esta parte do texto com a fala dos alunos, identificados com seus nomes e sobrenomes, porque é muito gratificante ter sua identidade reconhecida.

As falas compõem uma reportagem sobre o trabalho. Deixamos para o leitor a difícil tarefa de analisar se valeu a pena 'perder tempo'.

Foi legal porque eu aprendi que o patrimônio histórico não pode ser destruído. Há muitas coisas antigas e bonitas para se ver em Londrina. O meu avô sabe muitas histórias de locais importantes da cidade. A gente pode aprender muita coisa com o projeto. (Matheus Felipe dos Santos, 12 anos)

Foi interessante a atividade na Rua Sergipe, e gostei de escrever poesias. É fácil; é só aprender a brincar com as palavras. Foi a primeira vez que fui ao Bazar Ajimura e à Pastelaria do Jorge, e adorei o passeio; os dois foram muito gentis com a gente. Foi um projeto gostoso de fazer. (Marcsiel Lopes Bem, 11 anos) $)^{10}$ 


\section{O PROFESSOR DOS ANOS INICIAIS FRENTE AO SABER INDISCIPLINADO}

Essa experiência é ponto de partida para a última parte deste texto, na qual tecemos algumas elucubrações sobre a formação do professor para os anos iniciais. Entendemos que a ação de tal profissional pode ser compreendida com base na imagem de um caleidoscópio: saberes com epistemologias específicas que formam desenhos diversos com o reflexo dos espelhos.

Os saberes estão lá, cada um com sua cor e forma, e somente a sua diversidade gera a possibilidade do desenho. $\mathrm{O}$ desenho chama a atenção da criança. Para compor o desenho escolhem-se as cores e o tamanho dos espelhos. Um universo de possibilidades se compõe com algumas cores e formatos. Saber construir tal instrumento, saber compor os saberes tendo em vista os desenhos que se deseja formar é o que denominamos 'autonomia'.

$\mathrm{O}$ que se coloca para os professores e pesquisadores que atuam com a disciplina de metodologia e didática para o ensino de História nos cursos de Pedagogia é o desafio de ensinar a compor com autonomia e, paralelamente, garantir que a compreensão das características do saber histórico, assim como os demais saberes que se aliam ao saber histórico na escola, seja plena, a fim de se diferenciar cada campo do conhecimento.

Outro fator a ser considerado no processo de formação do professor para o trabalho com crianças é ditado pela diferença entre ensinar história para saber informações sobre o passado e ensinar história para pensar historicamente o mundo. Ainda que a segunda aprendizagem possa incluir a primeira, o reverso não se faz verdadeiro, e pode-se perfeitamente transmitir conjuntos de informações sem que elas estabeleçam conexões com a forma como o sujeito compreende a sua vida e sua ação na sociedade, projetando o futuro. Para compreender a vida, o sujeito precisa fazer uma tessitura entre passado, presente e futuro. A essa capacidade cognitiva denominamos 'pensar historicamente'.

\section{NOTAS}

${ }^{1}$ PINEAU, Gaston; LE GRAND, Jean-Louis. As histórias de vida. Trad. Carlos Eduardo Galvão Braga; Maria da Conceição Passeggi. Natal: EdUFRN, 2012. p.85. 
${ }^{2}$ FORQUIN, Jean-Claude. Escola e cultura: as bases sociais e epistemológicas do conhecimento escolar. Porto Alegre: Artes Médicas, 1993. p.169.

${ }^{3}$ PIAGET, Jean. Para onde vai a educação? Trad. Ivette Braga. 14.ed. Rio de Janeiro: J. Olympio Ed., 1998.

${ }^{4} \mathrm{O}$ Pibid conta com apoio financeiro da Capes.

${ }^{5}$ BAUMAN, Zygmunt. Identidade. Entrevista a Benedito Vecchi. Trad. Carlos Alberto Medeiros. Rio de Janeiro: Zahar, 2005.

${ }^{6}$ MONTOYA, Adrian Oscar Dongo. Piaget e a criança favelada: epistemologia genética, diagnóstico e soluções. Petrópolis (RJ): Vozes, 1996. p.18.

${ }^{7}$ MORAN, José Manuel. O vídeo na sala de aula. Comunicação \& Educação, São Paulo: Moderna, v.2, p.27-35, jan.-abr. 1995. p.28.

${ }^{8}$ CUSTÓDIO, José de Arimathéia Cordeiro. Do quadro de giz ao youtube. In: OLIVEIRA, D. E. M. B.; SANTOS, A. R. J.; REZENDE, L. A. (Org.). Formação de professores e ensino: aspectos teórico-metodológicos. Londrina (PR): EdUEL, 2011. p.177.

${ }^{9}$ BAKHTIN, Mikhail. Estética da criação verbal. Trad. Maria Ermantina G. G. Pereira. São Paulo: Martins Fontes, 1992. p.25-26.

${ }^{10}$ Folha de Londrina, 21 ago. 2012.

Artigo recebido em 20 de dezembro de 2012. Aprovado em 14 de abril de 2013. 